\title{
Effects of Bentonite Activation Methods on Chitosan Loading Capacity
}

\author{
Tao $\mathbf{Y u}^{1}$, Chengtun $\mathrm{Qu}^{2 *}$, Daidi Fan ${ }^{1}$, Renjun $\mathrm{Xu}^{3}$
}

${ }^{1}$ School of Chemical Engineering, Northwest University, Xi'an 710069, P.R. China

${ }^{2}$ College of Chemistry and Chemical Engineering, Xi'an Shiyou University, Xi'an 710065, P.R. China ${ }^{3}$ Department of Chemical Engineering, Xi'an Light Industry Research Institute, Xi'an 710001, P.R. China

Received: 14 $4^{\text {th }}$ March 2017; Revised: 17th July 2017; Accepted: $18^{\text {th }}$ July 2017

Available online: 22 $2^{\text {nd }}$ January 2018; Published regularly: 2 April 2018

\section{Abstract}

The adsorption capacity of bentonite clay for heavy metal removal from wastewater can be significantly enhanced by a high loading of chitosan on the surface. In order to enhance the chitosan loading, we tested activating bentonite clay by three methods prior to chitosan loading: sulfuric acid, calcination, and microwave treatments. Meanwhile, several parameters during chitosan loading, namely the initial chitosan concentration, stirring speed, reaction time, temperature, and $\mathrm{pH}$ value were investigated. Our results indicate that chitosan is attached to bentonite clay through intercalation and surface adsorption according to X-ray Diffraction (XRD), Scanning Eelectron Microscopy (SEM), and Fourier Transform Infrared Spectroscopy (FTIR) analyses. The maximum chitosan loading on 200-mesh raw bentonite clay $(126.30 \mathrm{mg} / \mathrm{L})$ was achieved under the following conditions: the initial chitosan concentration of $1000 \mathrm{mg} / \mathrm{L}$, the stirring speed of $200 \mathrm{rpm}, \mathrm{pH}$ of $4.9,60$ min of reaction time, and temperature of $30{ }^{\circ} \mathrm{C}$. The chitosan loading was further increased to 256.30 , 233.70 , and $208.83 \mathrm{mg} / \mathrm{g}$, when using bentonite clay activated through $6 \mathrm{~min}$ of microwave irradiation $(800 \mathrm{~W}), 10 \%$ sulfuric acid treatment, and calcinations at $600{ }^{\circ} \mathrm{C}$, respectively. When the chitosan loading was increased from 34.76 to $233.7 \mathrm{mg} / \mathrm{g}$, the removal percentages of $\mathrm{Cu}(\mathrm{II}), \mathrm{Cr}(\mathrm{VI}), \mathrm{and} \mathrm{Pb}(\mathrm{II})$ were improved, respectively from 78.90 to $95.5 \%$, from 82.22 to $98.74 \%$, from 60.09 to $86.18 \%$. Copyright (C) 2018 BCREC Group. All rights reserved

Keywords: Chitosan; Chitosan-loaded bentonite; Bentonite activation; Loading properties

How to Cite: Yu, T., Qu, C., Fan, D., Xu, R. (2018). Effects of Bentonite Activation Methods on Chitosan Loading Capacity. Bulletin of Chemical Reaction Engineering \& Catalysis, 13 (1): 14-23 (doi:10.9767/bcrec.13.1.1040.14-23)

Permalink/DOI: https://doi.org/10.9767/bcrec.13.1.1040.14-23

\section{Introduction}

Heavy metal ions are among the most hazardous compounds to human health and the environment due to their high level of toxicity, ability to enter the food chain, and poor biodegradability. Therefore, there are strict standards for their discharge into the environment.

* Corresponding Author.

E-mail: xianquct@163.com (Qu, C.)

Telp.: 029-8838 2699, Fax.: 029-8838 2699
Conventional methods for removing heavy metals from water include chemical precipitation, coagulation, flocculation, ion exchange, membrane filtration, and activated carbon adsorption $[1,2]$. However, these treatments tend to have high costs, leave residuals, and do not completely remove the pollutants. Hence, there is an urgent need to develop new low-cost adsorbents to remove heavy metals in water.

Natural bentonite clays are often used to adsorb metallic contaminants, since they are low- 
cost, abundant materials that have excellent cation exchange capacity and relatively large surface areas [3,4]. Chitosan modification of bentonite clay improves its effectiveness in water treatments, by mitigating certain flaws of bentonite clays, including high swelling and suspendability, difficult separation [5,6]. Meanwhile, bentonite clay remediates some disadvantages of chitosan that affect its adsorption efficacy, e.g. low density, the tendency to float, and difficulty in making contact with pollutants $[7,8]$. On the other hand, various modification techniques, including acid and thermal (by calcination or microwave radiation) treatments, have been reported to affect the adsorption properties of nature clays for metal ions in aqueous solutions [9-11].

Many studies of chitosan-loaded bentonite adsorbents have focused on their performance in pollution removal, such as the adsorption volume, particle size, optimal conditions $(\mathrm{pH}$, agitation rate, and temperature), equilibrium isotherm, related dynamics and thermodynamics, interfering ions, and the renewing of the adsorbents [12-14]. However, few studies have examined the process and mechanism of loading chitosan onto bentonite. Herein, for the first time, we investigated the effects of various parameters on the loading amount of chitosan: the initial amount of chitosan, stirring speed, $\mathrm{pH}$ value, reaction time, temperature and betonies activation/modification methods (e.g. acidification). Another novelty of the present study is that we compared the effects of the chitosan loading amount for removing $\mathrm{Cu}(\mathrm{II})$, $\mathrm{Cr}(\mathrm{VI})$, and $\mathrm{Pb}(\mathrm{II})$ ions from aqueous solutions. These studies indicate the process and mechanism of chitosan loaded onto bentonite and will surely extend the application of composite chitosan-loaded bentonite adsorbents for removing metal ions in wastewater.

\section{Materials and Methods}

\subsection{Reagents and equipment}

The following primary chemical reagents were used: bentonite clay (CTS, 300 mesh, Sinopharm Chemical Reagent Co., Ltd., Shanghai, China), chitosan (degree of deacetylation $\geq$ $90 \%$, Shanghai Lanji Biological Technology Co. Ltd), sulfuric acid (analytical grade), lead nitrate $\left(\mathrm{Pb}\left(\mathrm{NO}_{3}\right)_{2}\right.$, analytical grade), potassium dichromate $\left(\mathrm{K}_{2} \mathrm{CrO}_{7}\right.$, analytical grade), and hydrated copper sulfate $\left(\mathrm{CuSO}_{4} 5 \mathrm{H}_{2} \mathrm{O}\right.$, analytical grade).

Equipment used during the preparation of the adsorbents include: high-temperature boxtype resistance furnace ( SXL-1200, Zhengzhou
Honglang), microwave oven ( MG-5021, LG), 6paddle electrical stirrer with digital display (JJ-4, Changzhou Guowang), electrothermal constant-temperature water bath (DK-98-1, Shanghai Optical Instrument Factory), and high-speed desktop centrifuge (TGL-16G, Shanghai Anting). Instruments used for characterizing the properties and performance of the adsorbents include: UV spectrophotometer (200-1000 nm, UV-2350, Unico), Precision $\mathrm{pH}$ meter (0.00 14.00 pH, S20K, Mettler Toledo), Scanning electron microscope (HV mode Resolution: $3.0 \mathrm{~nm}, 8.0 \mathrm{~nm}, 15 \mathrm{~nm}, \mathrm{LV}$ mode Resolution: $4.0 \mathrm{~nm}$; Magnification: X5-X3000 000, JSM-6360LV, JEOL), X-ray powder diffractometer (Angle range: 5-120, Target: $\mathrm{Cu}$, Mo, $\mathrm{Fe}$, D8 Advance, Germa ny Bruker), and Infrared spectrometer (Spectrometer range: 7800$350 \mathrm{~cm}^{-1}$ (KBr), PE-680, Perkin-Elmer).

\subsection{Optimization of chitosan loading con- ditions}

The loading of chitosan on bentonite was examined using various reaction times (10-90 min), initial chitosan concentrations (250-2500 $\mathrm{mg} / \mathrm{L}$ ), stirring speeds (50-300 rpm), temperatures $\left(30-50^{\circ} \mathrm{C}\right)$, and $\mathrm{pH}$ values $(2-12)$. Specifically, $1 \mathrm{~g}$ of raw bentonite clay was dispersed in $150 \mathrm{~mL}$ of distilled water. The $\mathrm{pH}$ was adjusted with $\mathrm{HCl}$ and $\mathrm{NaOH}$ solutions. Chitosan solution of given concentration was then added to the bentonite suspension, up to a volume of $200 \mathrm{~mL}$.

\subsection{Activation and modification of ben- tonite clays}

The acid activation of bentonite clays has been prepared using $5 \mathrm{~g}$ of bentonite was placed in a $500 \mathrm{~mL}$ beaker, to which $200 \mathrm{~mL}$ of sulfuric acid solution of given concentration (5$30 \%)$ was added. The suspension was kept at $80^{\circ} \mathrm{C}$ and stirred at the rate of $500 \mathrm{rpm}$. After $4 \mathrm{~h}$ of reaction, the mixture was centrifuged, and then the precipitate was washed until the filtrate reached a $\mathrm{pH}$ value of 7.0-8.0. The clay was then dried, grinded, and sieved (200 meshes, $0.075 \mathrm{~mm}$ sieve size) [15]. To activate the clay by calcination, $5 \mathrm{~g}$ of bentonite clay was placed by a griddle in a muffler furnace, and calcinated at given temperature between $150-750{ }^{\circ} \mathrm{C}$ for $2 \mathrm{~h}$. After the oven cooled, the clay was grinded and sieved (200 meshes, $0.075 \mathrm{~mm}$ sieve size) [10]. For microwave activation, a griddle was used to place $5 \mathrm{~g}$ of bentonite clay in a microwave oven. The bentonite clay was then treated for 2-10 min at the output power of 300-1000 W [11]. 


\subsection{Determination of chitosan loading}

The primary amino groups of chitosan react chromogenically with Congo red under certain conditions, causing an absorption at $545 \mathrm{~nm}$ that is linearly proportional to the chitosan concentration $[16,17]$. On this basis, a spectrophotometric method was used to directly determine the content of chitosan. The standard curve in Figure 1 displays the following relationship (Equation (1)) between chitosan concentration $(y$, in $\mathrm{mg} / \mathrm{L})$ and light absorption (a.u.):

$$
\mathrm{y}=2277.2337 \mathrm{x}+45.1916
$$

The high linear correlation coefficient $\left(R^{2}=\right.$ 0.9973) indicates a good fit.

To load chitosan on bentonite, a chitosan solution of given concentration was slowly added to the bentonite suspension up to a volume of $200 \mathrm{~mL}$, and then the reaction was carried out at specified temperature and stirring speed for a fixed duration. The resulting mixture was centrifugally separated. The precipitate was heat-dried, grinded, and sieved (200 mesh, $0.075 \mathrm{~mm}$ sieve size) to obtain chitosan-loaded bentonite clay $[5,7]$. The amount of chitosan loading $\left(M_{c t}\right.$, in $\left.\mathrm{mg} / \mathrm{g}\right)$ was calculated as the difference between the initial amount of chitosan $\left(M_{q}\right)$ and that in the supernatant after the separation $\left(M_{q e}\right)$ (Equation (2)).

$$
M_{c t}=M_{q}-M_{q e}
$$

\subsection{Characterization and analysis}

To investigate the interactions between chitosan and bentonite, a Scanning Electron Microscopy (SEM, JSMLV-6360) was performed on raw, activated (by acidification, calcination, or microwave irradiation), and chitosan-loaded bentonite clays to analyze their microscopic

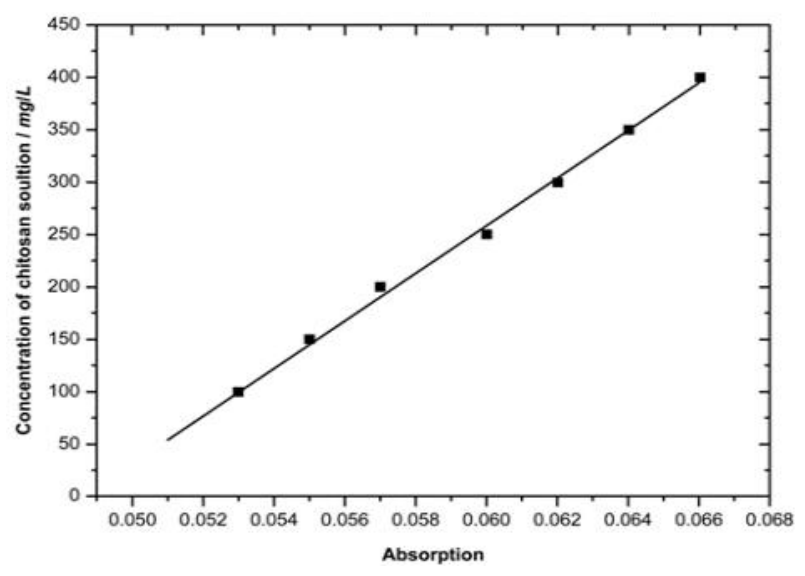

Figure 1. Standard curve for chitosan concentration measurement morphologies. An X-ray Diffraction (XRD, D8 Advance) was used to analyze the composition of the bentonite materials. The structural analysis was performed using a Fourier Transform Infra Red (FTIR) spectroscopy (PE-680 infrared spectrometer).

\subsection{Heavy metal ion adsorption experi- ments}

To test the performance of various clay adsorbents for removing heavy metals, the raw, activated, and chitosan-loaded bentonite clays were tested in aqueous solutions containing $\mathrm{Cu}(\mathrm{II}), \mathrm{Cr}(\mathrm{VI})$, or $\mathrm{Pb}$ (II) ions. Bentonite samples loaded with different amounts of chitosan were prepared after acidification for studying the effects of the adsorbent amount and chitosan loading. Single-metal solutions of $\mathrm{Cu}(\mathrm{II})$, $\mathrm{Pb}(\mathrm{II})$, and $\mathrm{Cr}(\mathrm{VI})(100 \mathrm{mg} / \mathrm{L})$ were prepared from the respective salts using distilleddeionized water, and their $\mathrm{pH}$ adjusted to $5.0 \pm$ 0.01 with $0.1 \mathrm{~mol} / \mathrm{L} \mathrm{HCl}$ or $\mathrm{NaOH}$. The metal ion contents in the solution were measured before and after adsorption, using a flame atomic absorption spectroscopy (Spectra AA 220FS, Varian, USA). The removal rate $\left(W_{e}, \%\right)$ was calculated in Equation (3).

$$
W_{e}=\frac{C_{0}-C_{e}}{C_{0}} \bullet 100 \%
$$

where $C_{0}$ and $C_{e}$ are the initial and equilibrium concentrations of the heavy metal ion $(\mathrm{mg} / \mathrm{L})$, respectively.

\section{Results and Discussion}

\subsection{Chitosan loading parameters}

According to Figure 2, the amount of chitosan loading increased with reaction time from

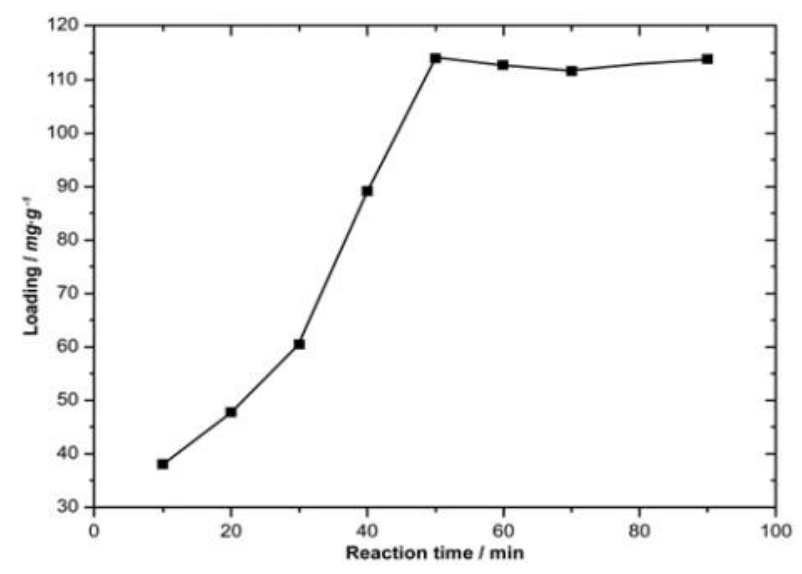

Figure 2. Effects of reaction time on chitosan loading 
10 to $50 \mathrm{~min}$, as more and more chitosan occupied the active adsorption sites on the bentonite [18]. The increase of chitosan loading became stagnant from 50 to $90 \mathrm{~min}$, with a maximum value of $112.62 \mathrm{mg} / \mathrm{g}$ after $50 \mathrm{~min}$ of reaction.

In Figure 3, the chitosan loading continuously increased with the initial chitosan concentration, reaching a plateau value of 108.83 $\mathrm{mg} / \mathrm{g}$ at $1000 \mathrm{mg} / \mathrm{L}$. At lower initial concentrations, active adsorption sites on the bentonite surface are not fully occupied, resulting in unsaturated loading [19]. The chitosan loading increased with the stirring speed used during the reaction, reaching a plateau value of 118.10 $\mathrm{mg} / \mathrm{g}$ at $200 \mathrm{rpm}$ (Figure 4). An appropriate stirring speed provides the necessary mass transfer for the loading process, while a lower speed leads to slower chitosan diffusion and consequently insufficient loading [20].

Figure 5 shows the effects of temperature on chitosan loading capacity. When the temperature increased from 30 to $50{ }^{\circ} \mathrm{C}$, the chitosan

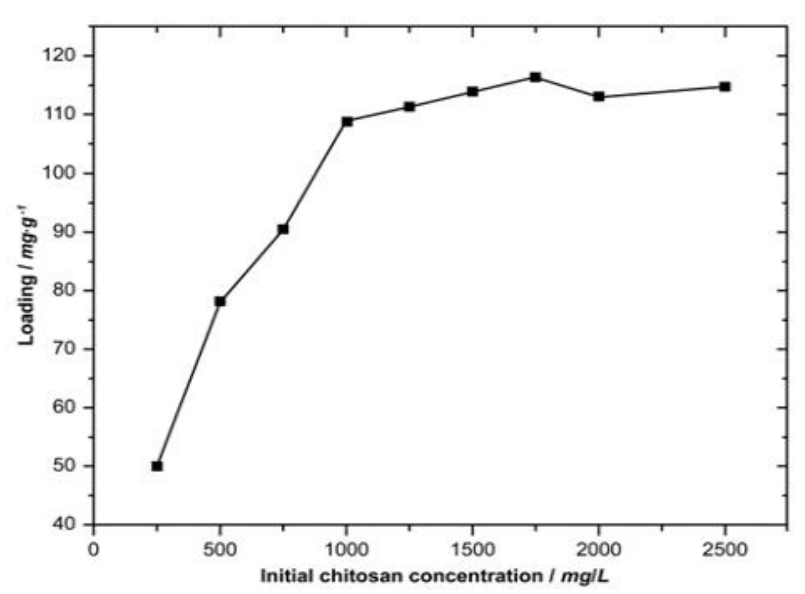

Figure 3. Effects of initial concentration on chitosan loading

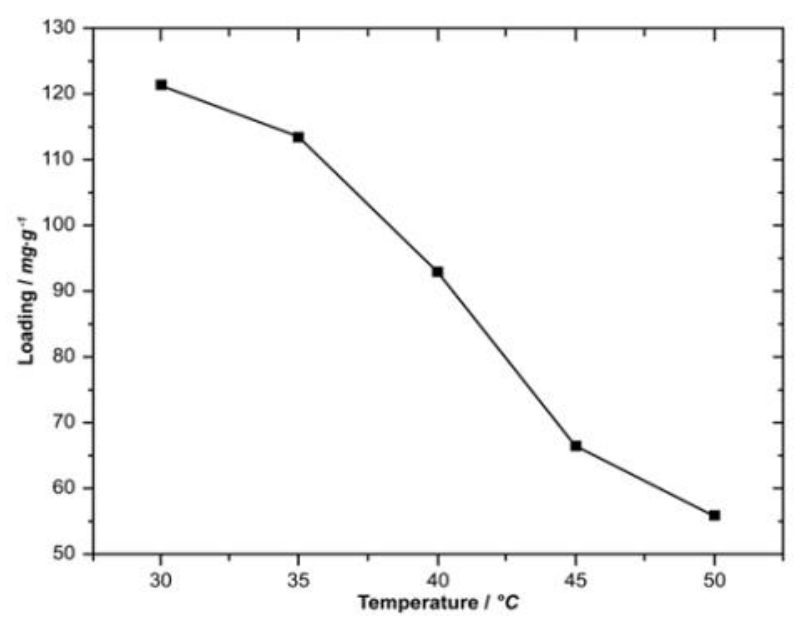

Figure 5. Effects of temperature on chitosan loading loading decreased from 121.48 to $55.98 \mathrm{mg} / \mathrm{g}$. As the temperature increases, the velocity of the chitosan molecules in the solution increases, which promotes chitosan desorption and reduces the loading. This trend also indicates that the loading of chitosan onto the bentonite surface is an exothermic reaction [21].

In Figure 6, as the $\mathrm{pH}$ value increased, the loading amount first increased to reach a maximum capacity of $126.30 \mathrm{mg} / \mathrm{g}$ at $\mathrm{pH}=4.88$, and then was lowered upon further $\mathrm{pH}$ increase. The main reason for these phenomena is that the $-\mathrm{NH}_{2}$ groups of chitosan molecules bond with $\mathrm{H}^{+}$in the solution to form $-\mathrm{NH}_{3}{ }^{+}$, which electrostatically interacts with the negatively charged surface of bentonite. At lower $\mathrm{pH}$ (i.e., higher $\mathrm{H}^{+}$concentration), however, $\mathrm{H}^{+}$can also compete with chitosan for the negatively charged loading sites. The protonation of the $-\mathrm{NH}_{2}$ groups and competitive adsorption, taken together, lead to an optimum $\mathrm{pH}$ for chitosan loading [22-24].

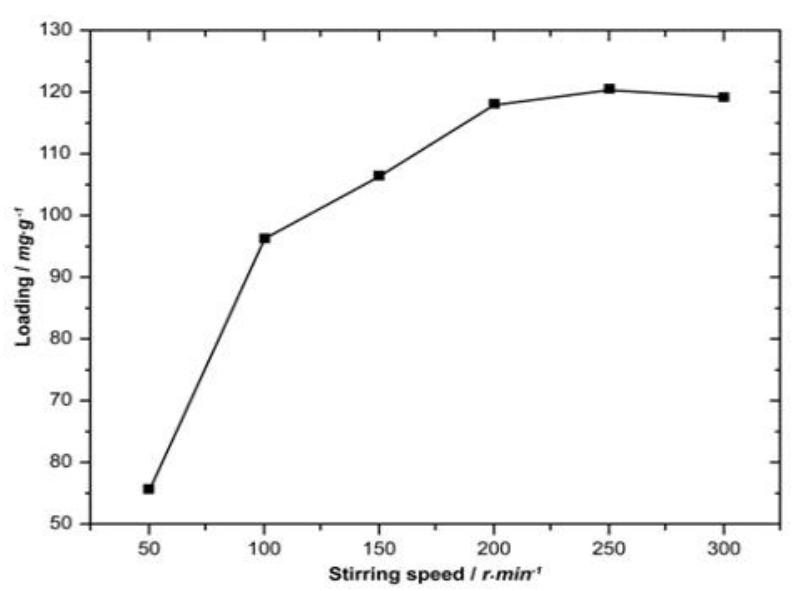

Figure 4. Effects of stirring speed on chitosan loading

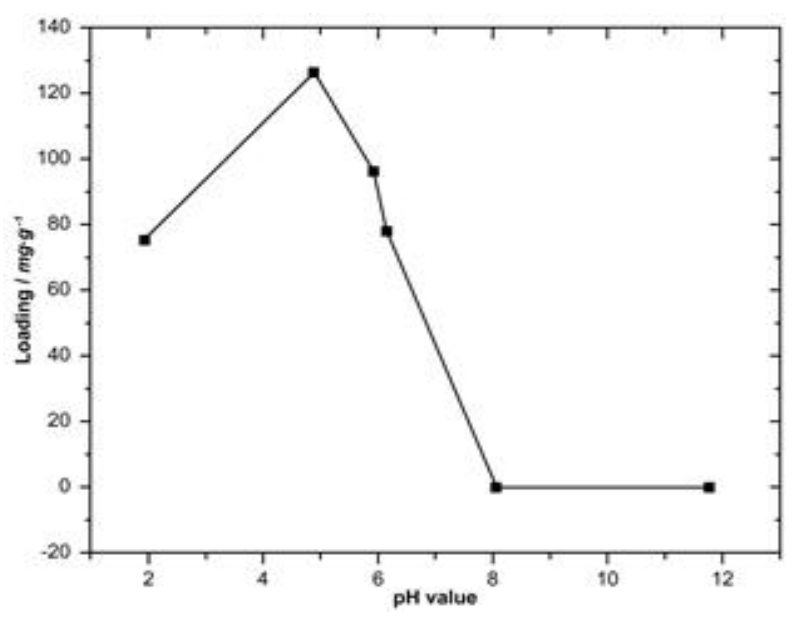

Figure 6. Effects of $\mathrm{pH}$ on chitosan loading 


\subsection{Effects of activation treatments on the chitosan loading amount}

Bentonite clay was activated by three different methods (acidification, calcination, and microwave irradiation), and then loaded with chitosan under the optimal conditions identified above (initial chitosan concentration: 1000 $\mathrm{mg} / \mathrm{L}$, stirring speed: $200 \mathrm{rpm}$, reaction time: 60 $\min , 30^{\circ} \mathrm{C}$, and $\mathrm{pH}=4.9$ ).

Sulfuric acid has the ability to remove the soluble salts and impurities from the surface and interlayers of bentonite, and thus it increases the surface area, porosity, and the number of chitosan loading sites in bentonite $[9,15,22]$. Figure 7 shows that the chitosan loading onto bentonite first increased and then decreased with the concentration of sulfuric acid (within 3-20\%) used. The maximum loading amount $(233.70 \mathrm{mg} / \mathrm{g}$ ) was found when using $10 \%$ sulfuric acid. In highly concentrated sulfuric acid, the layer of oxo ions within the bentonite structure could become dehydrated and fractured. As a result, the number of active loading sites for chitosan is reduced drastically.

The calcination process causes sequential loss of surface and then bonded water from bentonite, thus releasing more loading sites [10]. From Figure 8, the calcination activation of bentonite can enhance the loading capacity of chitosan. When the calcination temperature is increased from 150 to $750{ }^{\circ} \mathrm{C}$, the loading amount of chitosan first increases and then decreases, reaching a maximum $(208.83 \mathrm{mg} / \mathrm{g})$ at $600{ }^{\circ} \mathrm{C}$. A sufficiently high calcination temperature causes water loss and carbonates loss that improves adsorption ability of bentonite clay and increases the chitosan loading [23]. At excessively high temperatures, however, warping

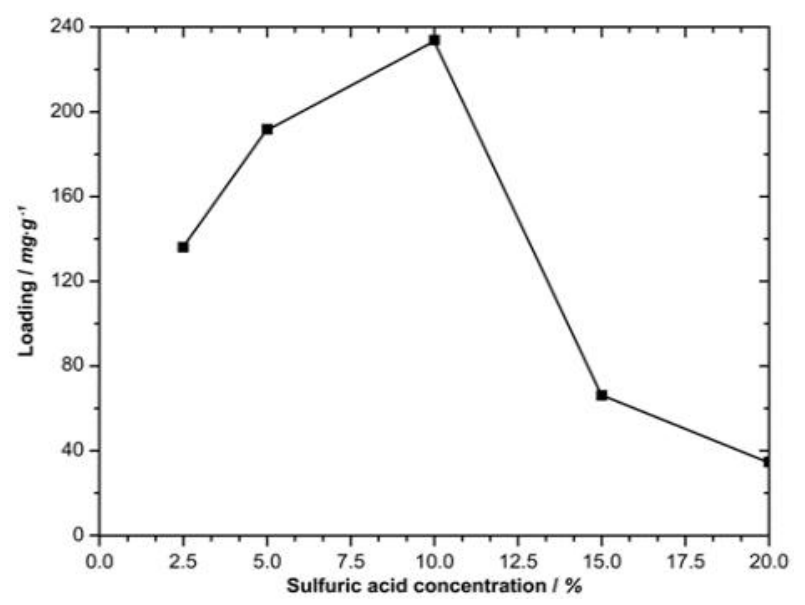

Figure 7. Effects of different concentrations of sulfuric acid used for activation on the loading of chitosan and shrinkage occur in bentonite, which damage its structural frame and reduce the number of available sites, thus causing the loading amount of chitosan to decrease.

Similar to the calcination method, microwave heating causes the superficially adsorbed and interlayer water to vaporize and escape, which in turn causes more pores and channels to form in bentonite. The result is an increased number of chitosan loading sites [11,24]. Based on Figures 9 and 10, the chitosan loading increases with the microwave radiation output power up to $800 \mathrm{~W}$ to reach a maximum of $193.01 \mathrm{mg} / \mathrm{g}$. At this output power, the loading amount first increased with the irradiation time and then decreased, with a maximum at 6 min to produce a chitosan loading of 256.30 $\mathrm{mg} / \mathrm{g}$. Upon prolonged irradiation, the channels and pores will "soften" and damage the original layered structure of bentonite, thus reducing the loading capacity.

According to the results above, all three activation methods can enhance the chitosan loading capacity on the bentonite surface. Both microwave irradiation and calcination can activate the bentonite clay by increasing the number of active sites for chitosan loading. Compared to these two methods, acidification is a high-efficiency, low-cost, and simple activation method for improving the chitosan loading capacity. Therefore, this method was used for the metal ion adsorption tests discussed in Section 3.4.

\subsection{Material characterization}

To obtain a better understanding of the microscopic morphology, composition, and structure of the various bentonite samples, SEM,

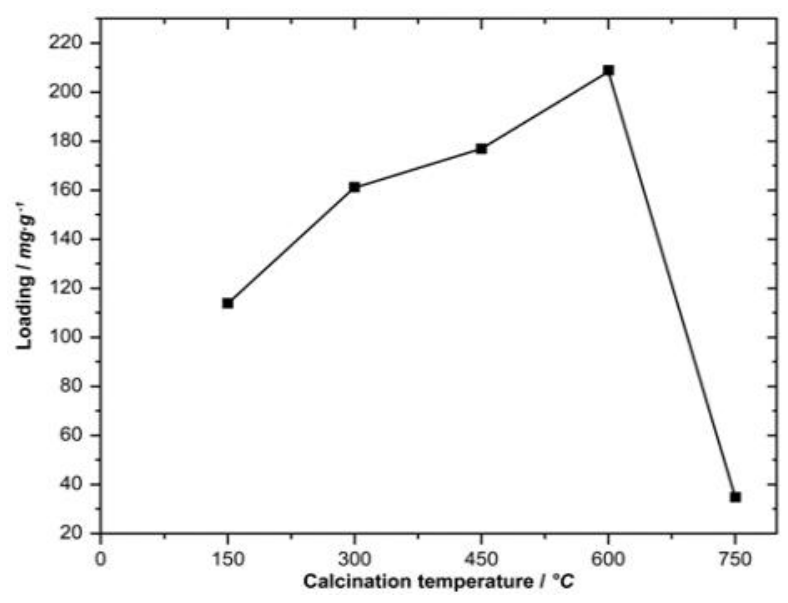

Figure 8. Effects of bentonite calcination temperatures on the loading of chitosan 
XRD, and FTIR analyses were performed on raw bentonite clay, bentonite activated by acidification, calcination, or microwaveirradiation (using the respective optimal treatment conditions), as well as chitosan-loaded bentonite.

As shown in Figure 11, the activated/modified bentonite clays, with and without chitosan, have smoother surfaces and more distinct spatial structures compared to the raw bentonite, and the particles were dispersed into smaller wafers. The white chitosan particles adsorbed onto the surface of chitosan-loaded bentonite (Figures 11(E) and 11(F)) and into the spaces between the clumps of clay cause the surface to become relatively coarser and looser, and the interlayer distances become significantly larger. These morphological changes

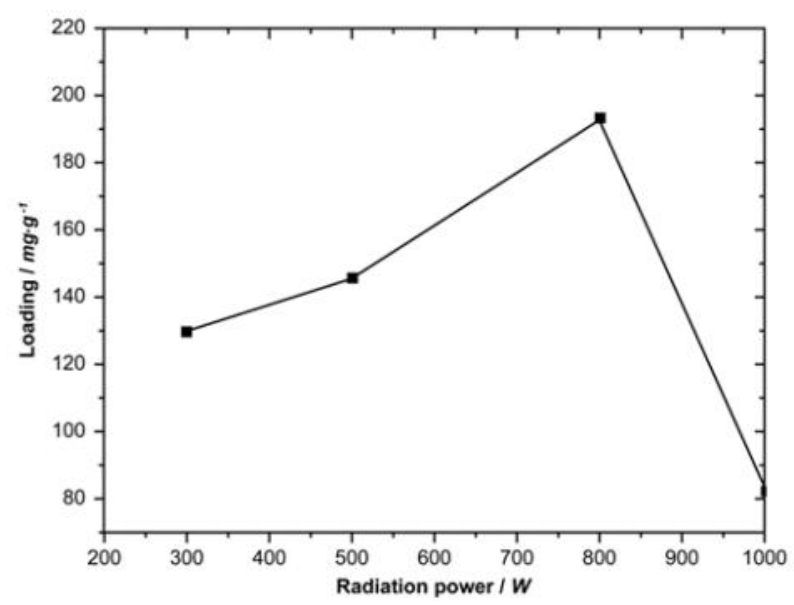

Figure 9. Effects of microwave radiation output powers used for activation on the loading of chitosan indicate that: (1) all three activation methods improve the spatial structure of bentonite; (2) chitosan is loaded via surface adsorption and intercalation; and (3) the loading process does not change the basic structure of bentonite [912].

In the XRD patterns of Figure 12, all activated bentonite samples have similar shapes in their diffraction patterns, although differences were observed in the position, sharpness, and symmetry of the $d(001)$ plane diffraction peak. The primary peak in the activated and chitosan-loaded activated clays shifted to smaller $2 q$ angles compared to the raw bentonite, especially in the chitosan-loaded activated clay. According to the Bragg equation, this change corresponds to an increase in the interlayer distances. Therefore, all three activation methods

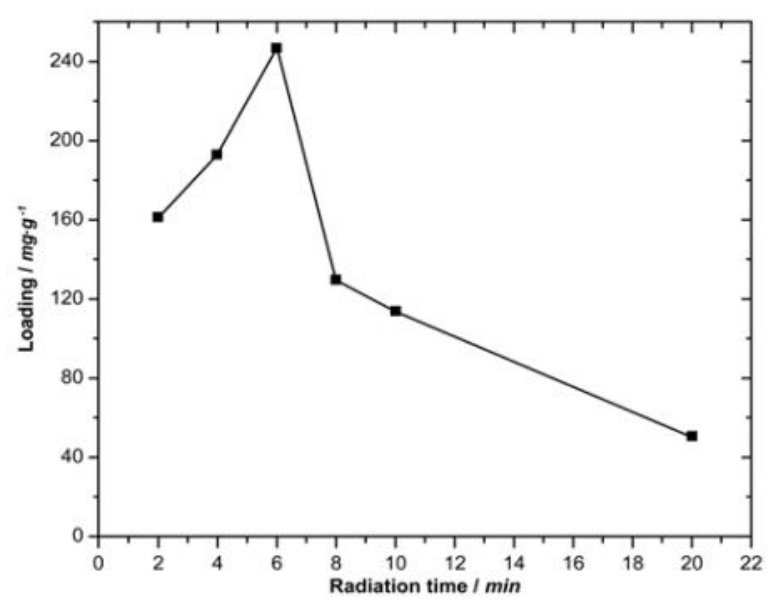

Figure 10. Effects of microwave radiation times used for activation on the loading of chitosan (Radiation power: $800 \mathrm{~W}$ )
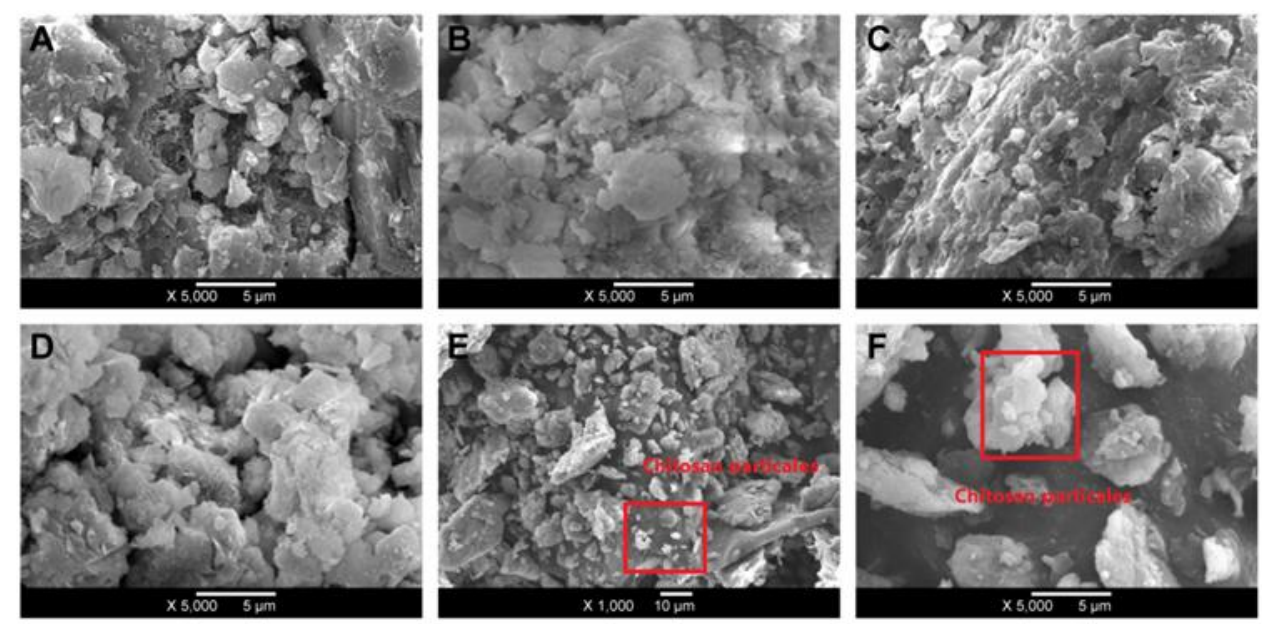

Figure 11. SEM images of different bentonite samples. (A) Raw bentonite clay, (B) acidified bentonite, (C) calcination-activated bentonite, (D) microwave-activated bentonite, (E) chitosan-loaded bentonite (x1000), (F) and chitosan-loaded bentonite (5000x) 
enhanced the interlayer structure of bentonite. The largest interlayer distance was observed in the chitosan-loaded activated bentonite, indicating that chitosan molecules could become intercalated between the bentonite layers [13,19,25].

In the FTIR spectra (Figure 13), both calcination and microwave activation caused the 3446 and $3589 \mathrm{~cm}^{-1}$ absorption peaks $(\mathrm{O}-\mathrm{H}$ stretching vibrations of water between the bentonite layers) to disappear. For the chitosanloaded bentonite, the new overlapping absorption peaks at around $3500 \mathrm{~cm}^{-1}$ is caused by the $\mathrm{O}-\mathrm{H}$ and $\mathrm{N}-\mathrm{H}$ stretching vibrations at similar frequencies. Another peak at $1518 \mathrm{~cm}^{-1}$ corresponds to $\mathrm{O}-\mathrm{H}$ bending vibrations, while those at 525 and $808 \mathrm{~cm}^{-1}$ correspond to the vibrations of octahedral Al-O. After chitosan loading, the area under the spectral peak at 540 $\mathrm{cm}^{-1}$ is reduced, while the peak at $1077 \mathrm{~cm}^{-1}$ becomes broader. These changes are due to the chemical adsorption of chitosan molecules on the octahedral $\mathrm{AlO}_{6}$, which weakens the $\mathrm{Al}-\mathrm{O}$ bond. According to these results, chitosan was successfully loaded (either on the surface or intercalated between the layers) onto bentonite clay without changing the basic structure of the latter $[5,13,26]$.

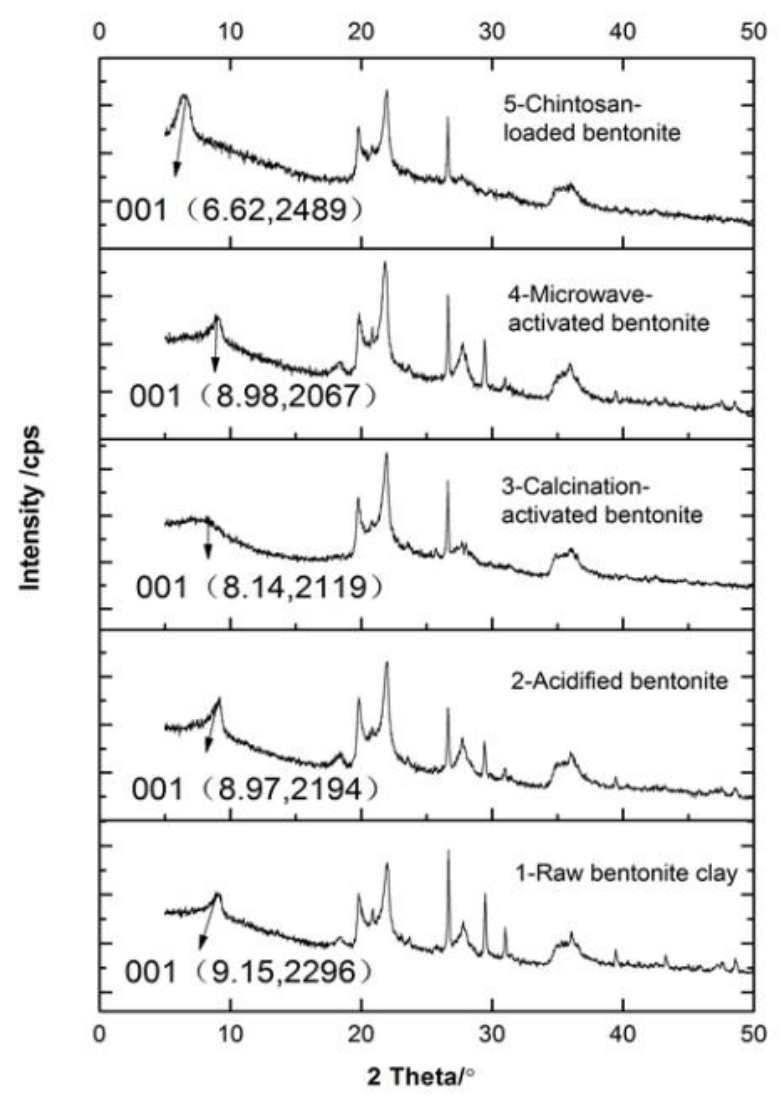

Figure 12. X-ray diffraction patterns of clay samples

\subsection{Adsorption performance of chitosan- loaded bentonite clay}

To test the capacity of the chitosan-loaded bentonite clays for adsorbing heavy metals, we tested various clay samples in $\mathrm{Cu}(\mathrm{II}), \mathrm{Cr}(\mathrm{VI})$, and $\mathrm{Pb}(\mathrm{II})$ solutions. For the chitosan-loaded bentonite, we also studied the effects of the adsorbent amount and the chitosan loading. Figure 14 shows the performance of the six clay samples for removing $\mathrm{Cu}(\mathrm{II}), \mathrm{Cr}(\mathrm{VI})$, and $\mathrm{Pb}(\mathrm{II})$ ions at $30^{\circ} \mathrm{C}$, with a stirring speed of $200 \mathrm{rpm}$, $\mathrm{pH}=5.0$ for $60 \mathrm{~min}$. The amount of adsorbent used was $1 \mathrm{~g} / \mathrm{L}$, and the initial ion concentrations were $100 \mathrm{mg} / \mathrm{L}$ each. All activation methods improved the performance of bentonite clay in adsorbing $\mathrm{Cu}(\mathrm{II}), \mathrm{Cr}(\mathrm{VI})$, and $\mathrm{Pb}(\mathrm{II})$, with the chitosan-modified clay showing a significant increase. Acidification, microwave irradiation, and calcination all increase the number of adsorption sites on bentonite and the cation exchange capacity, thus increasing the heavy metal adsorption capacity. Furthermore, the surface of the chitosan-modified clay features many amino and hydroxyl groups, which can form covalent bonds with the heavy metal ions and further improve the adsorption performance $[9,27]$.

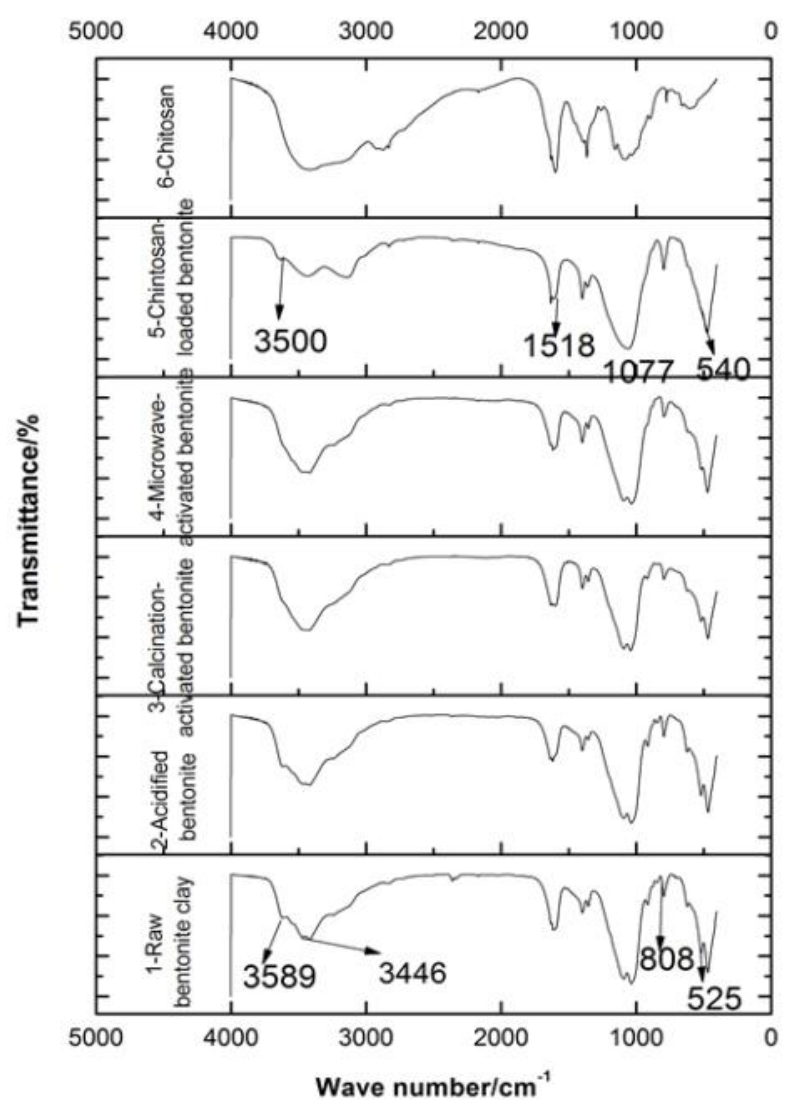

Figure 13. Infrared absorption spectra of clay samples 
Figure 15 shows the removal of $\mathrm{Cu}(\mathrm{II})$, $\mathrm{Cr}(\mathrm{VI})$, and $\mathrm{Pb}(\mathrm{II})$ heavy metal ions $(100 \mathrm{mg} / \mathrm{L})$ using chitosan-loaded bentonite at the adsorbent amounts of $0.5,1.0,1.5,2.0$, and $2.5 \mathrm{~g} / \mathrm{L}$. The adsorption was carried out at $30^{\circ} \mathrm{C}$, with a stirring speed of $200 \mathrm{rpm}, \mathrm{pH}=5.0$ for $60 \mathrm{~min}$. The removal percentage of all three heavy metal ions increased with the absorbent concentration, gradually reaching a plateau value. A higher amount of chitosan-loaded bentonite adsorbent means more adsorption sites available for the heavy metal ions, therefore the heavy metal ion removal is improved [28].

Finally, $1 \mathrm{~g} / \mathrm{L}$ bentonite clay samples loaded with different amounts of chitosan (34.76, 66.41, 136.22, 191.91, and $233.7 \mathrm{mg} / \mathrm{g}$ ) were tested with $100 \mathrm{mg} / \mathrm{L} \mathrm{Cu(II),} \mathrm{Pb}(\mathrm{II})$, or $\mathrm{Cr}(\mathrm{VI})$ solutions at $30{ }^{\circ} \mathrm{C}$, with a stirring speed of 200

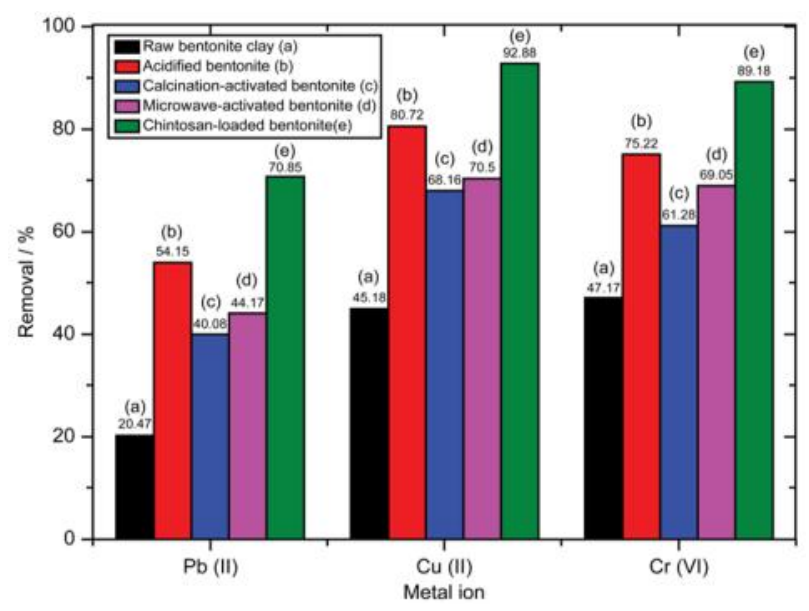

Figure 14. Comparison of $\mathrm{Cu}(\mathrm{II}), \mathrm{Pb}(\mathrm{II})$, and $\mathrm{Cr}(\mathrm{VI})$ removal percentages by different bentonite adsorbents

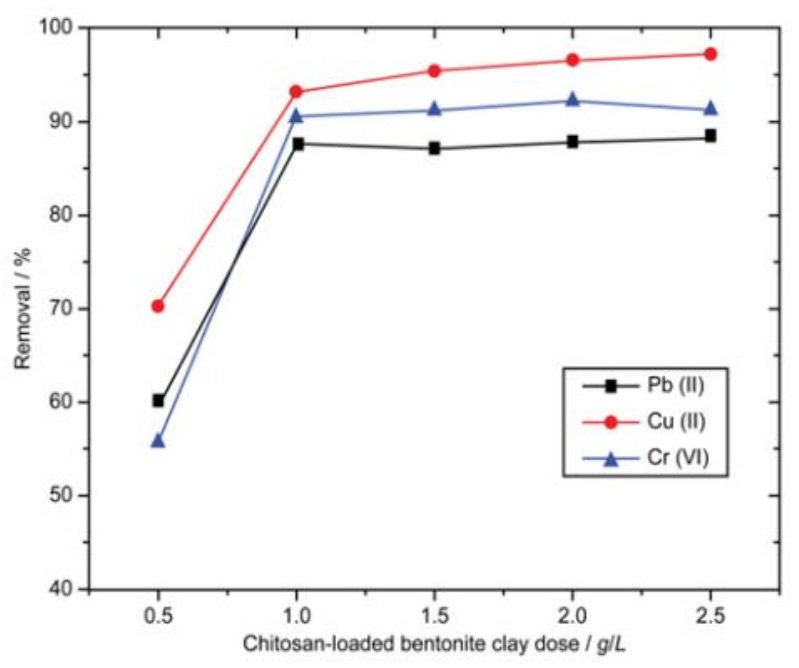

Figure 15. Effect of the amount of chitosanloaded bentonite on the heavy metal removal percentage rpm, $\mathrm{pH}=5.0$ for $60 \mathrm{~min}$ (Figure 16). The percentages of $\mathrm{Cu}(\mathrm{II}), \mathrm{Cr}(\mathrm{VI})$, and $\mathrm{Pb}(\mathrm{II})$ adsorption increased with the chitosan loading. An optimal chitosan loading should enhance the adsorption capacity of the clay, without clogging its adsorption channels (which is detrimental for the adsorption of heavy metal ions) $[6,28]$.

\section{Conclusions}

In this study, the loading capacity of chitosan increases and reaches a maximum value after $50 \mathrm{~min}$ of reaction with increasing reaction time. The chitosan loading increases with the initial chitosan concentration, and reaches a plateau value at $1000 \mathrm{mg} / \mathrm{L}$. At higher stirring speeds, the loading amount of chitosan increases to reach a plateau value at $200 \mathrm{rpm}$. When the temperature is increased from 30 to $50{ }^{\circ} \mathrm{C}$, the amount of chitosan loading is reduced. When the $\mathrm{pH}$ value is increased from 2 to 12 , the loading amount first increases, and then decreases, reaching a maximum loading capacity at $\mathrm{pH}=4.88$. For sulfuric acid from 3 to $20 \%$, the chitosan loading first increases and then decreases, with a maximum loading for $10 \%$ sulfuric acid. when the calcination temperature is increased from 150 to $750{ }^{\circ} \mathrm{C}$, with a maximum chitosan loading at $600{ }^{\circ} \mathrm{C}$. The chitosan loading following microwave radiation increases with the microwave output power, with a maximum loading at $800 \mathrm{~W}$. At this output power, the loading amount reaches a maximum loading at $6 \mathrm{~min}$. The removal percentages of $\mathrm{Cu}(\mathrm{II}), \mathrm{Cr}(\mathrm{VI})$, and $\mathrm{Pb}(\mathrm{II})$ all increase with the concentration of the adsorbent,

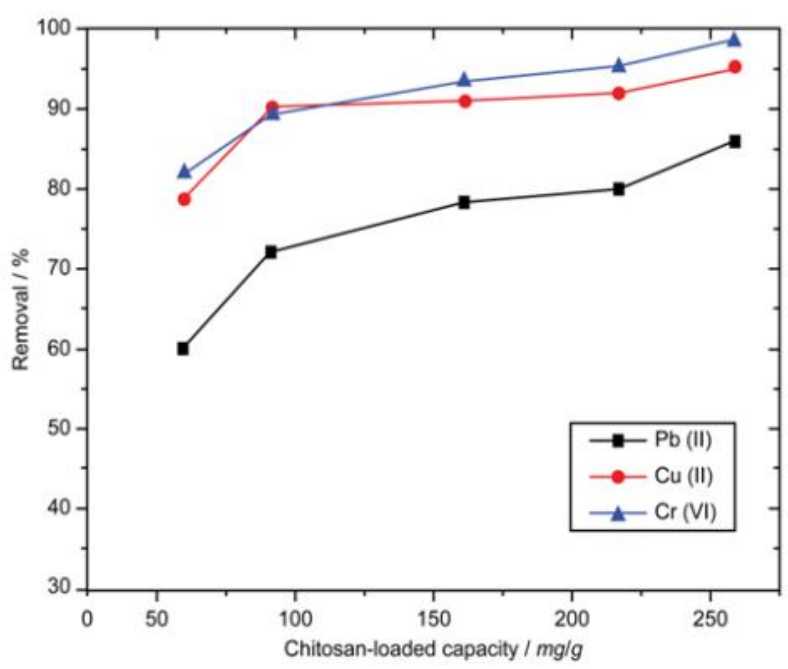

Figure 16. Effect of chitosan-loading on the heavy metal removal percentages by bentonite clay 
reaching a plateau value beyond $1 \mathrm{~g} / \mathrm{L}$ with $66.41 \mathrm{mg} / \mathrm{g}$ of chitosan loading.

\section{Acknowledgement}

This work was supported by the National Natural Science Foundation of China (Grant No. 21376189) and Special Scientific Research Project Foundation of the Science and Technology Department of Shaanxi Province (Grant No. 14JS087).

\section{References}

[1] Lim, A.P., Aris, A.Z. (2014). A Review on Economically Adsorbents on Heavy Metals Removal in Water and Wastewater. Reviews in Environmental Science and Bio/Technology, 13(2): 163-181.

[2] Zhao, M., Xu, Y., Zhang, C., Rong, H., Zeng, G. (2016). New Trends in Removing Heavy Metals from Wastewater. Applied Microbiology and Biotechnology, 100(15): 6509-6518.

[3] Liu, B., Wang, D., Yu, G., Xianghong, M. (2013). Adsorption of Heavy Metal Ions, Dyes and Proteins by Chitosan Composites and Derivatives - A Review. Journal of Ocean University of China, 12(3): 500-508.

[4] Sharma, P., Kaur, H., Sharma, M., Sahore, V. (2011). A Review on Applicability of Naturally Available Adsorbents for the Removal of Hazardous Dyes from Aqueous Waste. Environmental Monitoring and Assessment, 183(1): 151-195.

[5] Liu, Q., Yang, B., Zhang, L., Huang, R. (2015). Adsorptive Removal of $\mathrm{Cr}(\mathrm{VI})$ from Aqueous Solutions by Cross-Linked Chitosan/Bentonite Composite. Korean Journal of Chemical Engineering, 32(7): 1314-1322.

[6] Mohamed, R.R., Rizk, N.A., Abd El Hady, B.M., Abdallah, H.M., Sabaa, M.W. (2016). Synthesis, Characterization and Application of Biodegradable Crosslinked Carboxymethyl Chitosan/Poly(ethylene glycol) Clay Nanocomposites. Journal of Polymers and the Environment, doi:10.1007/s10924-016-0849-5.

[7] Olu-Owolabi, B.I., Popoola, D.B., Unuabonah, E.I. (2010). Removal of $\mathrm{Cu}^{2+}$ and $\mathrm{Cd}^{2+}$ from Aqueous Solution by Bentonite Clay Modified with Binary Mixture of Goethite and Humic Acid. Water, Air, \& Soil Pollution, 211(1): 459-474.

[8] Keng, P.S., Lee, S.L., Ha, S.T., Hung, Y.T., Ong, S.T. (2014). Removal of Hazardous Heavy Metals from Aqueous Environment by Low-Cost Adsorption Materials. Environmental Chemistry Letters, 12(1): 15-25.

[9] Khalfa, L., Cervera, M.L., Bagane, M., Souissi-Najar, S. (2016). Modeling of Equilib- rium Isotherms and Kinetic Studies of Cr (VI) Adsorption into Natural and Acid-Activated Clays. Arabian Journal of Geosciences, 9, 75.

[10] Falayi, T., Ntuli, F. (2015). Effect of Attapulgite Calcination on Heavy Metal Adsorption from Acid Mine Drainage. Korean Journal of Chemical Engineering, 32(4): 707-716.

[11] Riaz, U., Ashraf, S.M., Khan, N., (2011). Effects of Surfactants on Microwave-Assisted Solid-State Intercalation of Poly(carbazole) in Bentonite. Journal of Nanoparticle Research, 13(12): 6321-6331.

[12] El-Sherif, H., El-Masry, M. (2011). Superabsorbent Nanocomposite Hydrogels Based on Intercalation of Chitosan into Activated Bentonite. Polymer Bulletin, 66(6): 721-734.

[13] Ngah, W.S.W., Ariff, N.F.M., Hanafiah, M.A.K.M. (2010). Preparation, Characterization, and Environmental Application of Crosslinked Chitosan-Coated Bentonite for Tartrazine Adsorption from Aqueous Solutions. Water, Air, and Soil Pollution, 206(1): 225-236.

[14] Chen, Y., Zhu, C., Sun, Y., Duan, H., Ye, W., $\mathrm{Wu}$, D. (2012). Adsorption of La(III) onto GMZ Bentonite: Effect of Contact Time, Bentonite Content, $\mathrm{pH}$ Value and Ionic Strength. Journal of Radioanalytical and Nuclear Chemistry, 292(3): 1339-1347.

[15] Selvin, R., Hsu, H.L., Aneesh, P., Sha-Hua, C., Hung, L.L. (2010). Preparation of AcidModified Bentonite for Selective Decomposition of Cumene Hydroperoxide into Phenol and Acetone. Reaction Kinetics, Mechanisms and Catalysis, 100(1): 197-204.

[16] Raval, N.P., Shah, P.U., Shah, N.K. (2016). Adsorptive Amputation of Hazardous Azo Dye Congo Red from Wastewater: A Critical Review. Environmental Science and Pollution Research, 23(15): 14810-14853.

[17] Shahmirzadi, M.A.A., Hosseini, S.S., Tan, N.R. (2016). Enhancing Removal and Recovery of Magnesium from Aqueous Solutions by Using Modified Zeolite and Bentonite and Process Optimization. Korean Journal of Chemical Engineering, 33(12): 3529-3540.

[18] Chiu, F.C., Lai, S.M., Hsieh, I.C., Don, T.M., Huang, C.Y. (2012). Preparation and Properties of Chitosan/Clay (Nano) Composites: A Silanol Quaternary Ammonium Intercalated Clay. Journal of Polymer Research, 19(2): 9781. doi:10.1007/s10965-011-9781-5

[19] Kaya, E.M.Ö., Özcan, A.S., Gök, Ö., Özcan, A. (2013). Adsorption Kinetics and Isotherm Parameters of Naphthalene onto Natural- and Chemically Modified Bentonite from Aqueous Solutions. Adsorption, 19(2): 879-888. 
[20] Tonelli, D., Scavetta, E., Giorgetti, M. (2013). Layered-double-hydroxide-modified Electrodes: Electroanalytical Applications. Analytical and Bioanalytical Chemistry, 405(2): 603-614.

[21] Seyedmohammadi, J., Motavassel, M., Maddahi, M.H., Nikmanesh, S. (2016). Application of Nanochitosan and Chitosan Particles for Adsorption of $\mathrm{Zn}$ (II) Ions Pollutant from Aqueous Solution to Protect Environment. Modeling Earth Systems and Environment, 2(3):165. doi:10.1007/s40808-016-0219-2

[22] Hu, C., Hu, H., Zhu, J., Deng, Y., Li, C. (2016). Adsorption of $\mathrm{Cu}^{2+}$ on Montmorillonite and Chitosan-Montmorillonite Composite toward Acetate Ligand and the $\mathrm{pH}$ Dependence. Water, Air, \& Soil Pollution, 227: 362. doi: 10.1007/s11270-016-3067-9

[23] Chen, C.Y., Chung, Y.C. (2011). Comparison of Acid-soluble and Water-soluble Chitosan as Coagulants in Removing Bentonite Suspensions. Water, Air, \& Soil Pollution, 217(1): 603-610.

[24] Dong, Y., Lin, H.J. (2016). Ammonia Nitrogen Removal from Aqueous Solution Using Zeolite Modified by Microwave-Sodium Acetate. Journal of Central South University, 23(6): 13451352 .
[25] Lin, H., Jin, X., Dong, Y., Huo, H., Liu, Q. (2014). Influence of Calcination on the Physical Characteristics and Nitrogen Removal Performance of Clinoptilolites. Journal of Wuhan University of Technology-Mater. Sci. Ed., 29(6): 1099-1103.

[26] Sdiri, A.T., Higashi, T., Jamoussi, F. (2014). Adsorption of Copper and Zinc onto Natural Clay in Single and Binary Systems. International Journal of Environmental Science and Technology, 11(4): 1081-1092.

[27] Liu, J., Wang, H.L., Lü, C.X., Liu H.F., Guo, Z.X., Kang, C.L. (2013). Remove of Heavy Metals $\left(\mathrm{Cu}^{2+}, \mathrm{Pb}^{2+}, \mathrm{Zn}^{2+}\right.$ and $\left.\mathrm{Cd}^{2+}\right)$ in Water through Modified Diatomite. Chemical Research in Chinese Universities, 29(3): 445-448.

[28] Roque-Ruiz, J.H., Cabrera-Ontiveros, E.A., Torres-Pérez, J., Reyes-López, S.Y. (2016). Preparation of PCL/clay and PVA/clay Electrospun Fibers for Cadmium $\left(\mathrm{Cd}^{2+}\right)$, Chromium $\left(\mathrm{Cr}^{3+}\right)$, Copper $\left(\mathrm{Cu}^{2+}\right)$ and Lead $\left(\mathrm{Pb}^{2+}\right)$ Removal from Water. Water, Air, \& Soil Pollution, 227: 286. doi:10.1007/s11270-0162990-0 